\title{
Öğretmen Adaylarının Bilim İnsanlarının İsmiyle Özdeşleşen Bilimsel Terimlerin Yazımıyla İlgili Yanılgıları
}

\author{
Mehmet Yılmaz ${ }^{1}$, Osman Çimen ${ }^{1}$, Ferhat Karakaya ${ }^{1}$ \\ ${ }^{1}$ Matematik ve Fen Bilimleri Eğitimi Bölümü, Gazi Eğitim Fakültesi, Gazi Üniversitesi, Ankara, Türkiye
}

Sorumlu Yazar: Ferhat Karakaya, ferhatk26@gmail.com

Makale Türü: Araştırma Makalesi

Bilgilendirme: Bu makalede yer alan veriler, 23-25 Mart 2018, Afyonkarahisar, Türkiye'de düzenlenen "Uluslararası Bilim ve Eğitim Kongresi’nde (UBEK2018)” sözlü bildiri olarak sunulmuştur.

Kaynak Gösterimi: Yılmaz, M., Çimen, O., \& Karakaya, F. (2018). Öğretmen adaylarının bilim insanlarının ismiyle özdeşleşen bilimsel terimlerin yazımıyla ilgili yanılgıları. Eğitimde Kuram ve Uygulama, 14(4), 347-360. doi: 10.17244/eku.421145

\section{The Misconceptions of Pre-Service Teachers Regarding the Spelling of Terms Identified with the Names of Scientists}

\author{
Mehmet Yılmaz ${ }^{1}$, Osman Çimen ${ }^{1}$, Ferhat Karakaya ${ }^{1}$ \\ ${ }^{1}$ Department of Mathematics and Science Education, Gazi Faculty of Education, Gazi University, Ankara, Turkey
}

Corresponding Author: Ferhat Karakaya, ferhatk26@gmail.com

Article Type: Research Article

Acknowledgement: The data in this article was presented as an oral presentation in the International Congress of Science and Education (UBEK2018), 23-25 March, Afyonkarahisar, Turkey.

To Cite This Article: Yılmaz, M., Çimen, O., \& Karakaya, F. (2018). Öğretmen adaylarının bilim insanlarının ismiyle özdeşleşen bilimsel terimlerin yazımıyla ilgili yanılgıları. Eğitimde Kuram ve Uygulama, 14(4), 347-360. doi: 10.17244/eku.421145 


\title{
Öğretmen Adaylarının Bilim İnsanlarının İsmiyle Özdeşleşen Bilimsel Terimlerin Yazımıyla İlgili Yanılgıları
}

\author{
Mehmet Yılmaz ${ }^{1}$, Osman Çimen ${ }^{1}$, Ferhat Karakaya ${ }^{1}$ \\ ${ }^{1}$ Matematik ve Fen Bilimleri Eğitimi Bölümü, Gazi Eğitim Fakültesi, Gazi Üniversitesi, Ankara, Türkiye \\ ORCID: http://orcid.org/0000-0001-6700-6579 \\ ORCID: http://orcid.org/0000-0002-6651-6849 \\ ORCID: http://orcid.org/0000-0001-5448-2226
}

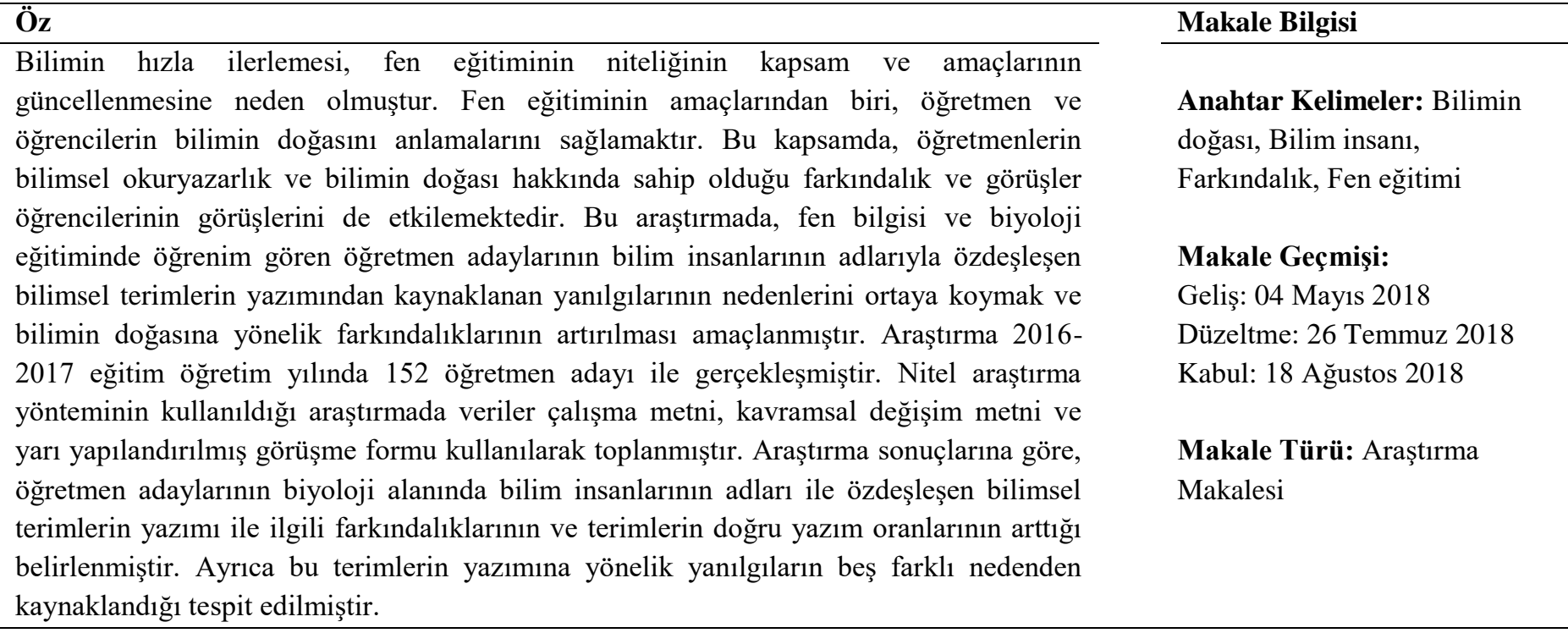

\section{The Misconceptions of Pre-Service Teachers Regarding the Spelling of Terms Identified with the Names of Scientists}

\section{Abstract}

The rapid progress of science has caused the scope and purpose of science education to be updated. One of the aims of science education is to ensure that teachers and students understand the nature of science. In this context, the awareness and opinions of teachers about scientific literacy and the nature of science affect the opinions of their students. This study was carried out to elucidate the reasons for the misconceptions of science and biology pre-service teachers regarding the spelling of terms associated with the names of the scientists and promote their awareness regarding these terms and the nature of science. The study was carried out with 152 pre- service teachers studying in Gazi University in 2016 - 2017 academic year. The study was based upon a qualitative research model and the data were collected using a study text, conception change text and semi-structured interview form. It has been determined that pre-service teachers' awareness of scientific terms that are identified with the names of scientists in the field of biology and the correct spelling rates of terms increase with increased awareness. It was also observed that the misconceptions for the written forms of these terms stem from five different reasons.
}

Article Info

Keywords: Nature of science, Scientist, Awareness, Science education

\section{Article History:}

Received: 04 May 2018

Revised: 26 July 2018

Accepted: 18 August 2018

Article Type: Research Article 


\section{Giriş}

Günümüz dünyasında bilimsel ve teknolojik alanlarda yaşanılan hızlı gelişmeler, okullarda öğrencilerin aldığı fen eğitiminin niteliğinin ve kalitesinin daha fazla önem kazanmasına neden olmuştur. Yaşanılan gelişmeler ülkelerin eğitim sisteminde değişiklikler yapmasını zorunda kılmıştır. Amerika Birleşik Devletleri ve pek çok Avrupa ülkesinde Fen eğitimin programları, öğrencilere daha fazla bilimsel bilgi aktarmak yerine, her öğrenciyi bilimsel düşünme becerilerine sahip "bilim/fen okur-yazarı" bireyler olarak yetiştirmeyi hedefleyecek şekilde düzenlenmiştir (Çakıcı, 2009). Ülkemizde Milli Eğitim Bakanlığı tarafından 2005 ve 2013 yıllarında Fen dersi öğretim programlarında düzenlemeler gerçekleştirilmiştir. 2005 yılı Fen ve Teknoloji Dersi Öğretim Programı'nın amacı, "bireysel farklı1ıkları ne olursa olsun tüm öğrencilerin fen ve teknoloji okuryazarı olarak yetiştirilmesi” olarak belirlenmiş (Milli Eğitim Bakanlığı [MEB], 2005) ve bu amaç 2013 yılında yeniden düzenlenen fen dersi öğretim programında aynen yer almıştır (Timur, Karatay \&Timur, 2013). Temel bilimsel kavramları ve çeşitli becerileri bünyesinde bulunduran bilim okuryazarlığının önemli bir parçası da bilimin doğasıdır (Köseoğlu, Tümay \& Üstün, 2010; Roberts, 2007). Bir toplumun bilim okuryazarlık konusunda iyi bir noktaya gelebilmesi için öncelikle öğrencilerin bilimin doğas1 hakkında yeterli seviyeye ulaşması gerekmektedir (American Association for the Advancement of Science [AAAS], 1993; National Research Council [NRC], 1996). Bilimin çok yönlü, karmaşık ve dinamik bir yapıya sahip olmas1 (Köseoğlu vd, 2010), bilimin doğası üzerinde bilim felsefecilerinin, tarihçilerinin ve sosyologlarının fikir ayrılıklarına yaşamasına neden olmaktadır (Abd-El-Khalick \& Lederman, 2000). Genel anlamda bilimin doğası, bilim epistemolojisi, sosyolojisi ve bilimsel bilgiye ait değerler ve inançlar olarak ifade edilmektedir (Lederman, 1992). McComas ve Olson (1998)' a göre ise, bilimin doğası, farklı alanları bir araya getirerek "bilim nedir, nasıl işler, bilim insanları nasıl çalışır, sosyal ve kültürel bağlamların bilime etkisi nedir?” gibi konuları incelemektedir.

Fen eğitiminin öncelikli amaçlarından birisi, öğretmen ve öğrencilerin bilimin doğasını yeterince anlamalarını ve geliştirmelerini sağlamaktır (Kang, Scharmann \& Noh, 2005). Öğretmen ve öğrencilerin bilimin doğasına yönelik inanışlarının geliştirilmesi için öğretim uygulamaları ve dönütleri büyük önem taşımaktadır (Aikenhead, 1997; Bravo, Matthews, 2000; Merce \& Anna, 2001). Nitekim Ortaöğretim Biyoloji Dersi Öğretim Programı (2017) incelendiğinde, Bilimsel Bilginin Doğası ve Biyoloji ünitesinde "Biyolojinin tarihsel gelişim sürecine katkı sağlayan bilim insanlarını tanır" kazanımına yer verildiği görülmektedir. Yapılan çalışmalar (Deniz \& Adıbelli, 2015; Hanuscin, Lee \& Akerson, 2011; Ratcliffe, 2008) öğretmenlerin sahip oldukları bilimin doğası anlayışının ve bilimin doğası öğretimlerinin, fen eğitim ve öğretimi açısından önemini bir kez daha ortaya koymuştur (Mıhladız \& Doğan, 2012).

Konu ile ilgili alanyazın incelendiğinde, öğretmenlerin bilimsel bilgiyi, bilim insanının özelliklerini ve toplum-bilim ilişkisini doğru şekilde aktardığında öğrencilerin bilimsel düşünce gelişimlerinde pozitif etki oluşturduğu belirlenmiştir (Khishfe, 2008; Zeidler, Walker, Ackett \& Simmons, 2000). Bilimsel okuryazarlık ve bilimin doğasını anlamaya yönelik çalışmalar (Gess-Newsome, 2002; Khishfe \& Abd-El Khalick, 2002; Lederman, 1999; NRC, 1996; Posnanski, 2010; Soloman, Scott \& Duveen, 1996; Taber, 2008) eğitim uygulamalarının gerekliliğini vurgulamıştır. Uluslararası alanyazında öğrenci ve öğretmenlerin bilimin doğasına yönelik bakış açılarını belirlemek için farklı ölçek çalışmalarının olduğu görülmüştür. Türkiye'de araştırmacıların, veri toplamak için Aikenhead, Ryan ve Fleming (1989) tarafindan deneysel yolla geliştirilen ve 114 çoktan seçmeli sorudan oluşan "Fen'in Doğası Hakkındaki Görüşler" (VOSTS)" anketi içinden maddeler seçilerek Türkçeye uyarlanan VOSTS-TR anketini kullandıkları görülmektedir (Aslan, Yalçın \& Taşar 2009; Aslan, 2010; Aslan \& Taşar, 2013; Ayvacı \& Özbek, 2015; Çetin 2009; Çınar \& Köksal, 2013; Doğan-Bora, Arslan \& Çakıroğlu, 2006; Doğan, Çakıroğlu, Çavuş, Bilican \& Arslan, 2011; Mıhladız, 2010; Mıhladız \& Doğan, 2012; Zorlu \& Baykara, 2015).

Uluslararas1 (Abd-El-Khalick \& BouJaoude, 1997; Chen, 2001; Tairab, 2001) ve ulusal (Yakmac1, 1998; Taşar, 2003; Erdoğan, 2004; Doğan, 2005; Aslan, Yalçın \& Taşar, 2009) araştırmalarda, eğitimin farklı kademelerinde yer alan öğretmen ve öğrencilerin bilimin doğasına yönelik görüşlerinin yeterli düzeyde olmadığı ve yanlış kavrama sahip oldukları belirlenmiştir. Ayrıca uluslararası alanyazında ülkelerin eğitim-öğretiminde kullandıkları fizik, kimya ve biyoloji ders kitapları incelenmiş ve kitapların bilimin doğasını temsil etme düzeylerinin belirlendiği araştırmalar yer almaktadır (Abd-El-Khalick vd, 2017; DiGiuseppe, 2013; Vesterinen vd, 2013).

Bilimin doğasının öğrenciler tarafından anlaşılamamasının nedenlerinden birisi öğretmenlerin bilimin doğası hakkında yeterli görüşlerinin olmamasıdır (Lederman, 1992). Bilimsel okuryazarlık ve bilimin doğası hakkında öğretmenlerin sahip olacağı farkındalık ve görüşler öğrencilerinin görüşlerini de etkilemektedir (Water-Adams, 2006). $\mathrm{Bu}$ nedenle geleceğin eğitim sisteminde yer alacak olan öğretmen adaylarının bilimin doğasına yönelik 
farkındalıklarının artırılması ve bilimin doğasına yönelik görüşlerini geliştirecek çalışmaların yapılması önem kazanmaktadır. Nitekim Türkiye'de "1739 sayılı Millî Eğitim Temel Kanunu'nun 2. maddesinde ifade edilen Türk Millî Eğitiminin Genel Amaçları ile Türk Millî Eğitiminin Temel İlkeleri esas alınarak hazırlanan Biyoloji Dersi Öğretim Programında" öğrencilerin Bilim tarihi süreci içerisinde biyoloji alanına katkı sağlayan bazı bilim insanlarını tanımaları özel amaç olarak hedeflenmiştir. Bu özel amaç sayesinde ortaöğretimde öğrenim gören öğrencilerin bilimin doğasına yönelik farkındalıkları artırılması sağlanacaktır. Öğretim programında yer alan özel amacın hedeflerine ulaşabilmesinde öğretmenlere büyük sorumluluklar düşmektedir. $\mathrm{Bu}$ noktada araştırmanın alanyazına katkı sağlayacağı düşünülmektedir.

\section{Araştırmanın Amacı}

$\mathrm{Bu}$ araştırmada, Fen bilgisi ve Biyoloji eğitiminde öğrenim gören lisans, formasyon ve yüksek lisans öğrencilerinin bilimin doğası kapsamında, bilim insanlarının adlarıyla özdeşleşen bilimsel terimlerin yazımında, bu terimlerin özel isim olduğuna dikkat edilmemesinden kaynaklanan yanılgılarının nedenlerinin ortaya koyulması ve bilimin doğasına yönelik farkındalıklarının artırılması amaçlanmıştır. Bu amaç doğrultusunda aşağıdaki sorulara cevap aranmıştır:

1. Biyoloji alanında bilim insanlarının adları ile özdeşleşen bilimsel terimlerle ilgili yapılan uygulama öğretmen adaylarında nasıl değişim sağladı?

2. Biyoloji alanında bilim insanlarının adları ile özdeşleşen bilimsel terimlerin yazılmasıyla ilgili öğretmen adaylarının bugüne kadar sahip olduğu yanılgılar neden kaynaklanmaktadır?

\section{Yöntem}

\section{Araştırmanın Modeli}

$\mathrm{Bu}$ araştırmada nitel araştırma yöntemlerinden durum çalışması kullanılmıştır. Durum çalışması, bir sistem içerisinde gerçekleşen durum ya da olayların detaylandırılarak açıklanmasını ifade etmektedir (Creswell, 2007).

\section{Araştırmanın Çalışma Grubu}

Araştırmanın çalışma grubu, Gazi Üniversitesinde öğrenim gören Fen bilgisi ve Biyoloji eğitiminde öğrenim gören lisans, formasyon ve yüksek lisans öğrencilerinden oluşmaktadır. Araştırma 2016-2017 akademik yılında hayata geçirilmiştir. Araştırmanın çalışma grubuna ait frekans ve yüzde dağılımı Tablo 1'de verilmiştir.

Araştırmanın çalışma grubunda yer alan biyoloji öğretmen adaylarını lisans eğitiminin ilk 3.5 (üç buçuk) yılında alan dersleri sonraki 1.5 (bir buçuk) yılında ise alan eğitimi dersleri görmektedirler. Bu nedenle araştırmada 3.sınıf ve 5.sınıf düzeyinde öğrenim gören biyoloji öğretmen adayları tercih edilmiştir.

Tablo 1. Araştırma grubunun frekans, yüzde dağılımı

\begin{tabular}{llll}
\hline & & Frekans (n) & Yüzde (\%) \\
\hline \multirow{2}{*}{ Fen bilgisi öğretmen adayı } & 3. sinıf & 32 & 21.1 \\
\cline { 2 - 4 } & 4. sınıf & 29 & 19.1 \\
\hline \multirow{2}{*}{ Biyoloji öğretmen adayı } & 3. sınıf & 8 & 5.3 \\
\cline { 2 - 4 } & 5. sinıf & 12 & 7.9 \\
\hline \multirow{2}{*}{ Yüksek lisans öğrencisi } & Fen Bilgisi eğitimi & 18 & 11.8 \\
\cline { 2 - 4 } & Biyoloji eğitimi & 21 & 13.8 \\
\hline Formasyon öğrencisi & & 32 & 21.1 \\
\hline Toplam & & 152 & 100.0 \\
\hline
\end{tabular}

\section{Verilerin Toplanması}

Araştırmada veriler, araştırmacılar tarafından hazırlanan biyoloji çalışma metni, kavramsal değişim metni ve yarı yapılandırılmış görüşme formu aracılığıyla toplanmıştır. Metinlerin hazırlanmasında, fen bilgisi ve biyoloji eğitiminde çok sık kullanılan ve bilimsel okuryazarlık bakımından hata yapılan başlıklar seçilmiştir. Yarı yapılandırılmış görüşme formu, iki adet açık uçlu sorudan oluşmaktadır. Veriler aşağıdaki aşamalar gerçekleştirilerek toplanmıştır:

a) Çalışma metni, araştırmanın çalışma gruplarına cümleler halinde okunarak katılımcılardan bunları yazmaları istenmiştir.

b) Amaca yönelik hazırlanan kavramsal değişim metni çalışma gruplarına dağıtılarak incelemeleri istenmiştir. 
c) Çalışma gruplarına iki hafta sonra uygulamaya konu olan bilim insanlarının ismiyle özdeşleşen biyolojik kavramlar verilerek bunları içeren anlamlı cümleler yazmaları istenmiştir.

d) Araştırmaya katılan öğretmen adayları arasından (her bir gruptan öğretmen adayı olacak şekilde) gönüllülük esasına göre belirlenen 16 kişiyle yarı yapılandırılmış görüşme formu yazılı olarak uygulanmıştır. Katılımcıların formlara isim yazmamaları istenmiş ve verdikleri bilgilerin sadece bu bilimsel çalışmada kullanılacağ1 belirtilmiştir. Katılımc1lardan toplanan formlar Ö1,Ö2,Ö3,...Ö16 şeklinde kodlanmış ve katılımcı görüşlerini yansıtan ifadeler bu kodlar kullanılarak aslına uygun şekilde alıntılanmıştır.

İçerik analizinde görüşmelerden elde edilen veriler dikkatli bir şekilde okunmuş ve araştırmanın amaçları doğrultusunda ortaya çıkan anlamlara göre kodlar oluşturulmuştur. Kodlanan veriler incelenerek benzerlik ve farklılıklarına göre gruplandırılmıştır. Daha sonra birbiriyle ilişkili olan kodlar bir araya getirilerek temalar oluşturulmuştur.

\section{Bulgular}

Bu bölümde araştırmaya katılan öğretmen adaylarının, bilimin doğasına yönelik farkındalıklarının artırılması amacıyla hazırlanan metinler ve bilim insanlarının adlarıyla özdeşleşen bilimsel terimlerin yazımından kaynaklanan yanılgıların sebeplerine yönelik elde edilen veriler sunulmuştur.

Araştırmada ilk olarak "Biyoloji alanında bilim insanlarının adları ile özdeşleşen bilimsel terimlerle ilgili yapılan uygulama ögretmen adaylarında nasıl değişim sağladı?” sorusuna cevap aranmış ve elde edilen sonuçları Tablo 2 ve Tablo 3'te verilmiştir.

Tablo 2'deki veriler incelendiğinde, araştırmaya katılanların en çok yanlışı Corti organının yazımında ( $\mathrm{f}=137$; \%90.1), en çok doğruyu ise Turner sendromunun yazımında ( $\mathrm{f}=105 ; \% 69.1)$ yaptıkları belirlenmiştir.

Tablo 2. Çalı̧̧ma metni uygulamalarının frekans, yüzde dağılımı

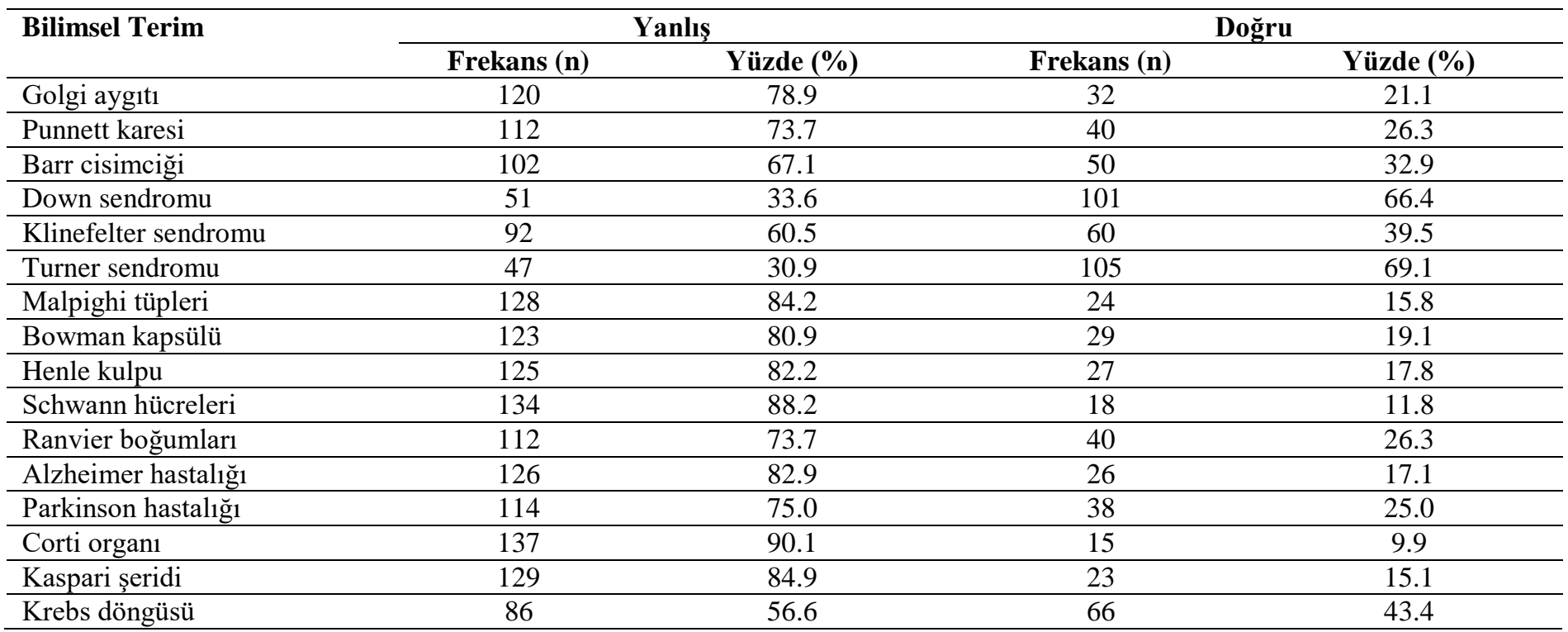

Tablo 3'deki veriler incelendiğinde, araştırmaya katılanların en çok yanlışı Corti organının yazımında ( $\mathrm{f}=140$; \%92.1), en çok doğruyu ise Golgi aygıtının yazımında ( $\mathrm{f}=152 ; \% 100)$ yaptıkları belirlenmiştir.

Kavramsal değişim metni uygulamasından sonra araştırmaya katılan öğretmen adaylarının bilim insanları ile özdeşleşen terimlere yönelik farkındalık ve terimlerin doğru yazımı ile ilgili öne çıkan görüşlerinden bazıları aşağıda sunulmuştur.

Ö4:Öğretmen olduğum günden itibaren ögrencilerime bu şekilde doğru yazmalarını öğretmeye gayret göstereceğim ve bu terimlerin bilim insanlarının isimleri olduğuna ve büyük harfle yazılması gerektiğini anlatacağım.

Ö8:Bu tür biyolojik terimlerin yazımına dikkat etmem gerektiğini anladım. Bunların farkında olunması gerektiğini ve çok ufak detayların önemli etkiler yarattığını anladım.

Ö10:Söylenen kelimeler üzerinde kimse bana daha önceden vurgu yapmadl. Yani yanlıs yapmam ilkokuldan beri uyarılmamış olmamdan kaynaklanmaktadır. Bu çalışma sırasında yanlışlarımın farkına vardım. 
Ö14: Öğretmen olduğumda öğrencilerime bu kavramları ögretirken kim tarafindan ve nasıl bulunduğunu öğreteceğim. Bu sayede öğrencilerim kavramları ezberlemeden öğrenecek ve derslerinde bu kavramları doğru bir şekilde kullanacaklar.

Tablo 3. Kavramsal değişim metni uygulamalarının frekans, yüzde dağılımı

\begin{tabular}{|c|c|c|c|c|}
\hline \multirow[t]{2}{*}{ Bilimsel Terim } & \multicolumn{2}{|c|}{ Yanlış } & \multicolumn{2}{|c|}{ Doğru } \\
\hline & Frekans (n) & Yüzde (\%) & Frekans (n) & Yüzde (\%) \\
\hline Golgi aygitı & 0 & 0 & 152 & 100.0 \\
\hline Punnett karesi & 76 & 50.0 & 76 & 50.0 \\
\hline Barr cisimciği & 102 & 67.1 & 50 & 32.9 \\
\hline Down sendromu & 4 & 2.6 & 148 & 97.4 \\
\hline Klinefelter sendromu & 65 & 42.8 & 87 & 57.2 \\
\hline Turner sendromu & 6 & 3.9 & 146 & 96.1 \\
\hline Malpighi tüpleri & 96 & 63.2 & 56 & 36.8 \\
\hline Bowman kapsülü & 47 & 30.9 & 105 & 69.1 \\
\hline Henle kulpu & 31 & 20.4 & 121 & 79.6 \\
\hline Schwann hücreleri & 117 & 77.0 & 35 & 23.0 \\
\hline Ranvier boğumları & 67 & 44.1 & 85 & 55.9 \\
\hline Alzheimer hastalığ 1 & 115 & 75.7 & 37 & 24.3 \\
\hline Parkinson hastalığ1 & 11 & 7.2 & 141 & 92.8 \\
\hline Corti organı & 140 & 92.1 & 12 & 7.9 \\
\hline Kaspari şeridi & 15 & 9.9 & 137 & 90.1 \\
\hline Krebs döngüsü & 46 & 30.3 & 106 & 69.7 \\
\hline
\end{tabular}

Araştırmada "Biyolojik terimlerin yazılmastyla ilgili ögretmen adaylarının bugüne kadar sahip olduğu yanılgılar neden kaynaklanmaktadır?” sorusuna cevap aranmış ve elde edilen sonuçlar Şekil 1'de verilmiştir.

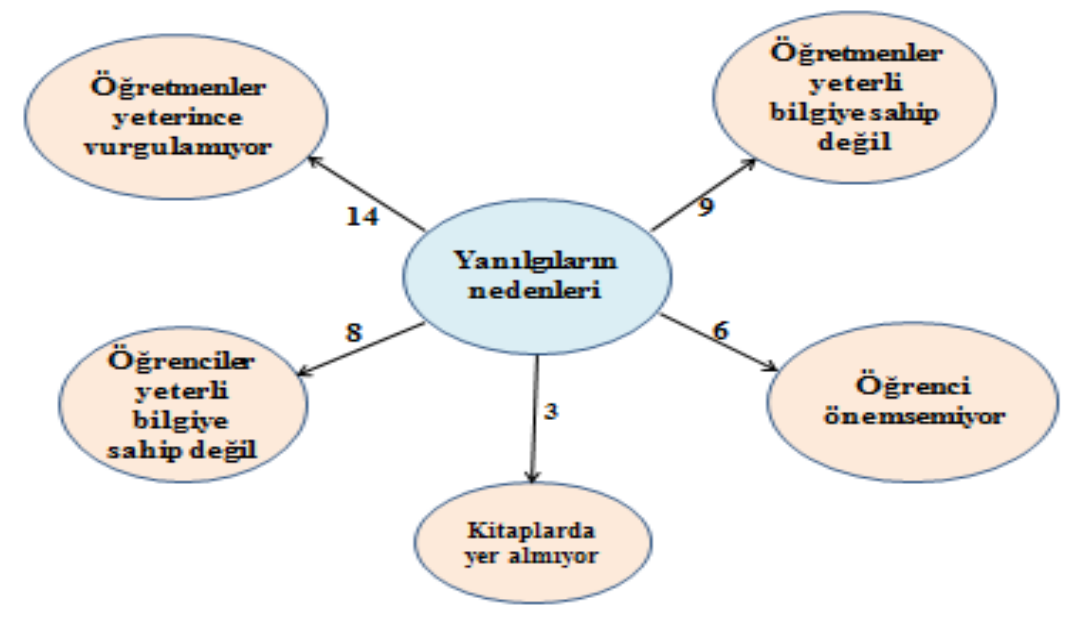

Şekil 1. Yanılgı nedenlerine yönelik temalar ve frekans dağılımı

Şekil 1'deki bulgular incelendiğinde, Biyoloji alanında bilim insanlarının adları ile özdeşleşen bilimsel terimlerin yazılmasıyla ilgili öğrencilerin bugüne kadar sahip olduğu yanılgıların beş farklı nedenden kaynaklandığı görülmektedir. Araştırmaya katılan öğrenciler kendilerindeki bu şekildeki yanılgıların en önemli nedeninin “öğrenimleri sırasında öğretmenlerin bilim insanlarının adıyla özdeşleşen bilimsel terimleri yeterince vurgulamamasından kaynaklandığını' belirtmişlerdir. Katılımcılar tarafından, öğretmenlerin biyoloji alanında bilim insanlarının adları ile özdeşleşen bilimsel terimlerin yazılmasıyla ilgili yeterli bilgiye sahip olmadıklarını ifade etmeleri dikkat çekici bir bulgu olarak görülmüştür. Bu konuda öne çıkan öğrenci görüşlerinden bazıları aşağıda sunulmuştur. 
Ö4: Daha önceden bize bu konuları ögreten ögretmenlerimiz bunların bilim insanı isimleri olduklarını bahsetmediklerinden, konuyu tahtaya yazarken yazıma dikkat etmediklerinden ve yazarken yeterince vurgu yaparak anlatmadıklarından dolayı bu zamana kadar ben bunların bilim insanı isimleri oldukların bilmeden geldim.

Ö5:Öğrencilerin eğitim hayatı boyunca fen dersi aldıkları ögretmenlerin derslerinde kullandikları özel isimleri belirtmeden kullanmaları yanlış yazmamin nedenidir.

Ö8:Bilimsel terimler kullanırken dikkat etmeden yazmamın sebeplerinden biri okulda bunların bizlere laylkiyla anlatılmamasıdır.

Araştırmaya katılan öğrenciler, bugüne kadar sahip olduğu yanılgıların bir diğer nedeni olarak da öğretmenlerinin bu terimlerin yazımı hakkında yeterince bilgiye sahip olmadıklarından kaynaklandığını belirtmiş̧lerdir. Bu konuda öne çıkan öğrenci görüşlerinden bazıları aşağıda sunulmuştur.

Ö1:Öğretmenlerin dersleri anlatırken ya da onları yazdıkları zaman yanlış yazmalarından dolayı ögrenciler de yanlış yazmaktadırlar.

Ö7:Öğretmenlerin hazır bulunuşluk ve deneyimleri az olduğundan bu kavramların yazımında öğrenciler hata yapmaktadır. Öğretmenlerin yanlışları doğrudan öğrenciyi de yanlışa yönlendirmektedir.

Araştırmaya katılan öğrenciler, bugüne kadar sahip olduğu yanılgıların bir diğer nedeni olarak da ortaöğretim ders kitaplarında bu terimlerin yazımı hakkında bilginin yer almadığından kaynaklandığını belirtmişlerdir. Bu konuda öne çıkan öğrenci görüşlerinden bazıları aşağıda sunulmuştur.

Ö2: Bu terimlerin bilim insanlart ile ilgili olduğuna dair kitaplarda bir bilgiye daha önce rastlamadım.

Ö8: Lise ders kitaplarında bu terimler küçük harf ile yazllyyor. Bu nedenle bende öyle öğrendim.

Ö15: Gerek ders kitaplarında gerekse soru bankalarında bu terimlerin bilim insanlarlyla özdeşleşen bilimsel terimlerine yönelik bilgi veya vurguyu hiç görmedim.

\section{Tartışma ve Sonuç}

$\mathrm{Bu}$ araştırmada Fen bilgisi ve Biyoloji eğitiminde öğrenim gören veya mezun olan öğretmen adaylarının bilimin doğası kapsamında, bilim insanlarının adlarıyla özdeşleşen bilimsel terimlerin yazımından kaynaklanan yanılgılarının nedenlerinin ortaya koyulması ve bilimin doğasına yönelik farkındalıklarının artırılması amaçlanmıştır.

Araştırma kapsamında, öğretmen adaylarının çalışma metninde en çok yanlışı Corti organının yazımında, en çok doğruyu ise Turner sendromunun yazımında yaptıkları belirlenmiştir. Araştırmada öğrencilerin biyoloji alanında bilim insanlarının adları ile özdeşleşen bilimsel terimlerin yazımı ile ilgili farkındalıklarını artırmak amacıyla kavramsal değişim metni uygulanmıştır. Kavramsal değişim metni sonucunda öğrencilerin en çok yanlış1 Corti organının yazımında, en çok doğruyu ise Golgi cisimciği yazımında yaptıkları belirlenmiştir. Çalışma metni bulguları (Tablo 2) ve kavramsal değişim metni bulguları (Tablo 3) karşılaştırıldığında, araştırmaya katılan öğrencilerin biyoloji alanında bilim insanlarının adları ile özdeşleşen bilimsel terimlerin yazımı ile ilgili farkındalıklarının ve terimlerin doğru yazım oranlarının arttığı belirlenmiştir. Alanyazın incelendiğinde bilimin doğası etkinliklerinin öğrencilerin bilimsel süreç becerilerine olumlu katkı sağladığını belirten araştırmaların (Arslan, 1995; Can \& Pekmez, 2010; Carey \& Evans, 1989; Rivas, 2003; Roberts, 2001) olduğu belirlenmiştir. Ayrıca bazı araştırmalarda (Bartholomew, Osborne \& Ratcliffe, 2004; Doğan vd., 2011) öğretmenlerin öğretim programlarında hedeflenen bilim eğitimi verebilmeleri için üniversiteden başlamak üzere hizmet içi eğitimlerin verilmesi gerektiği vurgulanmıştır. Bu sonuçlar araştırmanın bulgularını desteklemektedir.

Araştırmada, biyoloji alanında bilim insanlarının adları ile özdeşleşen bilimsel terimlerin yazılmasıyla ilgili öğrencilerin bugüne kadar sahip olduğu yanılgıların beş farklı nedenden kaynaklandığı belirlenmiştir. Araştırma bulguları incelendiğinde (Şekil 1), biyoloji alanında bilim insanlarının adları ile özdeşleşen teknik terimlerin yazılmasıyla ilgili öğrencilerin bugüne kadar sahip olduğu yanılgıların en önemli nedeninin, öğretmenlerin bu terimleri yeterince vurgulamadıklarından kaynaklandığı tespit edilmiştir. Alan yazına bakıldığında birçok araştırmada (Abd-El-Khalick \& Lederman, 2000b; Aslan, 2009; Mihladız \& Doğan, 2012; Murcia \& Schibeci, 1999; Tsai, 2002) öğretmen ve öğretmen adaylarının bilimin doğası konusunda yetersizliğinin olduğu tespit edilmiştir. Canbazoğlu (2008)'na göre, öğretmen adaylarının uygulama sürecinde deneyimlerinin artması onların programa yönelik bilgilerini de artıracaktır. Leden ve diğerleri (2015) yaptıkları araştırma sonucunda, öğretmenlerin bilimin doğasına yönelik ihtiyaçlarının farkında oldukları ancak bu ihtiyaçların giderilmesi için nasıl uygulamalar yapmaları gerektiğini bilmediklerini belirtmiştir. Mıhladız ve Doğan (2012) yaptıkları araştırma sonucunda, öğretmen adaylarının bilimin 
doğası konusunda bilgi eksikliklerinin olduğunu belirlemişlerdir. $\mathrm{Bu}$ sonuçlar araştırmanın bulgularını desteklemektedir. Ayrıca kitaplarda bilim insanların isimleriyle özdeşleşen bilimsel terimlere yönelik bilgilerin yer almaması ve bu terimlerin ders kitaplarında yanlış yazılmaları öğretmen adayların yanılgılarının nedenlerinden biri olarak belirlenmiştir. Milli Eğitim Bakanlığı tarafından ortaöğretim biyoloji dersi kapsamında okutulan ders kitaplarında bu terimlerin yazımı ile ilgili hataların olması ve bu terimlerin bilim insanlarıyla özdeşleşen bilimsel terimler olduğuna dair bilgilerin yeterince yer almaması araştırmanın bulgusunu desteklemektedir.

\section{Öneriler}

$\mathrm{Bu}$ araştırma sonucunda biyoloji alanında bilim insanlarının adları ile özdeşleşen bilimsel terimlerin yazılmasıyla ilgili öğretmen adaylarının yanılgılarının olduğu belirlenmiştir. Ayrıca öğretmen adaylarının bu yanılgılarının nedenleri ortaya çıkartılmıştır. Araştırma bulgularına göre aşağıdaki önerilere yer verilmiştir:

- Alanyazında bilim insanlarının adının verildiği bilimsel terimlerden bahsedilirken özel isim yazım kuralına göre bu terimlerin büyük harfle başlayarak yazılması gerektiği vurgulanmalıdır.

- Bu tür bilimsel terimlerin geçtiği yerlerde, ilgili bilim insanlarının hayatı ve çalışmalarından örneklerin yer aldığı küçük okuma parçaları verilebilir. $\mathrm{Bu}$ uygulamaların öğrencilerin ilgili konuyu kodlayarak öğrenmelerinde ve bilimsel terimlerin yazımında daha duyarlı davranmalarında etkili olacağı öngörülmektedir.

- Öğretmenlerin ders anlatımları sırasında böyle bir bilimsel terimin bir bilim insanının çalışmasına atfen verildiğini vurgulamaları, gerek sınıf içi ve gerekse sınav uygulamalarında buna dikkat etmeleri gerekli görülmektedir.

- Araştırma kapsamı genişletilerek farklı çalışma gruplarına uygulanabilir. 


\section{Extended Summary}

\section{Introduction}

Rapid developments in science and technology in today's world have led to the importance of the quality of science education that students have received. This situation has forced countries to make changes in the education system. Many countries, especially the United States and European countries, have updated their science curricula. Turkey has also updated the science curriculum. Science education programs are designed to target each student as "science / science literate" individuals with scientific thinking skills, rather than giving more scientific information to the students (Çakıc1, 2009). Arrangements in science teaching programs were made by the Ministry of Education in Turkey (MEB, 2005; 2013). The aim of the Science and Technology Curriculum was determined as "educating all students, regardless of individual differences, in science and technology literacy" (Milli Eğitim Bakanlığı[MEB], 2005) and this aim was exactly observed in the science course curriculum reorganized in 2013 (Timur, Karatay \& Timur, 2013). An important part of science literacy, that holds basic scientific concepts and various skills, is the nature of science (Köseoğlu, Tümay \& Üstün, 2010, Roberts, 2007). According to McComas and Olson (1998), the nature of science brings together different fields and examines issues like "what is science, what works, how do scientists work, what is the influence of social and cultural contexts?" The understanding of the nature of science is very important. However, the nature of science is not fully understood by students. One of the reasons why the nature of science is not understood by students is that teachers do not have enough opinions about the nature of science (Lederman, 1992).

Teachers have a great responsibility to raise awareness of the nature of science for secondary school students. This study was carried out to elucidate the reasons for the misconceptions of the science and biology pre-service teachers regarding the spelling of the terms identified with the names of scientists and promote their awareness regarding these terms and the nature of science.

\section{Methodology}

In this case study, qualitative research methods were used. The case study describes in detail the situation or events occurring within a system (Creswell, 2007). The study group consisted of undergraduates, postgraduates and persons who receive educational pedagogy courses but are not graduated from education faculties. 152 pre-service teachers were studying in the Department of Science Education and Biology Education in a state university, Turkey. The research was conducted in the 2016-2017 academic year. In the research, data were collected with a biology study text, conceptual change text, and semi-structured interview form prepared by the researchers. In the preparation of the texts, chapters were used which are frequently used in science and biology education and included mistakes in terms of scientific literacy. The semi-structured interview form consisted of two open-ended questions. In the content analysis, the data obtained from the interviews were generated in line with the objectives of the research. The coded data were examined and grouped according to their similarities and differences. Then, the codes related to each other were put together and the themes were created.

\section{Discussion and Conclusion}

In this context, the awareness and opinions of teachers about scientific literacy and the nature of science affect the opinions of their students. This study was carried out to elucidate the reasons for the misconceptions of the science and biology pre-service teachers regarding the spelling of the terms identified with the names of the scientists and promote awareness regarding these terms and the nature of science. In the study, when the writings of the pre-service teachers were examined, it was determined that the most frequently misspelt term was Corti and the most accurate one was Turner syndrome.

As a result of the conceptual change text, it was determined that the students made the most mistakes in the writing of Corti, and the most correctly written one was Golgi. It was determined that the students who participated in the research increased the correct spelling rates and the awareness related to the writing of scientific terms which are identified with the names of scientists in the field of biology. When the literature is examined, it is determined that the nature activities of science contribute positively to the scientific process skills of the students (Arslan, 1995; Can \& Pekmez, 2010; Carey \& Evans, 1989; Roberts, 2001, Rivas, 2003). 
The research has identified five different reasons for the misconceptions that students in the field of biology have had about writing scientific terms associated with scientists' names. When the research findings were examined (Figure 1), it was found that the most important reason for the misconceptions that students in the field of biology have to date about the technical terms associated with the names of scientists is that teachers do not emphasize these terms sufficiently. In the literature, it has been found in many studies that teachers and pre-service teachers are inadequately informed about the nature of science (Abd-El-Khalick \& Lederman, 2000b; Aslan, 2009; Mihladiz \& Doğan, 2012; Murcia \& Schibeci, 1999; Tsai, 2002). Leden et al., (2015) found that teachers were aware of the natural needs of science, but they do not know how to implement factors in order to overcome these needs.

As a result of this research it has been determined that in the field of biology there are mistakes of pre-service teachers related to the writing of scientific terms which are identified with the names of scientists. Moreover, the reasons for these misconceptions of teacher candidates have been revealed. 


\section{Kaynakça / References}

Abd-El-Khalick, F., Myers, J. Y., Summers, R., Brunner, J., Waight, N., Wahbeh, N., ... \& Belarmino, J. (2017). A longitudinal analysis of the extent and manner of representations of nature of science in US high school biology and physics textbooks. Journal of Research in Science Teaching, 54(1), 82-120.

Abd-El-Khalick, F., \& Lederman, N. G. (2000a). Improving science teachers conceptions of the nature of science: A critical review of the literature. International Journal of Science Education, (22), 665-701.

Abd-El-Khalick, F. \& Lederman N. G. ( 2000b). The Infuence of history of science courses on students' views of nature of science. Journal of Research in Science Teaching, 37(10), 1057-1095.

Abd-El-Khalick, F., \& BouJaoude, S. (1997). An exploratory study of knowledge base for science teaching. Journal of Research in Science Teaching, 34(7), 673-699.

Aikenhead, G. S. (1997). Toward a first nations cross-cultural science and technology curriculum. Science Education, 81(2), 217-238.

American Association for the Advancement of Science (1993). Benchmarks for science literacy: A project 2061 report. NewYork: Oxford University Press.

Arslan, A. (1995). Illkokul öğrencilerinde gözlenen bilimsel beceriler. (Yayımlanmamış Doktora Tezi). Hacettepe Üniversitesi Sosyal Bilimler Enst. Ankara.

Aslan, O. (2010). Fen ve teknoloji öğretmenlerinin bilimsel bilginin doğası hakkındaki görüşleri. EJournal of New World Sciences Academy Education Sciences, 6(1), 20-31.

Aslan, O., Yalçın N. \& Taşar M. F. (2009). Fen ve Teknoloji öğretmenlerinin bilimin doğası hakkındaki görüşleri. Ahi Evran Üniversitesi Ë̆itim Fakültesi Dergisi, 10(3), 1-8.

Aslan, O. (2009). Fen ve teknoloji ögrretmenlerinin bilimin doğası hakkındaki görüşleri ve bu görüşlerin slnıf uygulamalarına yansımaları, Yayımlanmamış Doktora Tezi, Gazi Üniversitesi Eğitim Bilimleri Enstitüsü, Ankara.

Ayvacı H. Ş. \& Özbek D. (2015). Fen teknoloji toplum dersi kapsamında yapılan uygulamaların fen bilimleri öğretmen adaylarının bilimin doğası algılarına etkisi. Hasan Ali Yücel Eğitim Fakültesi Dergisi, 12-1(23), 131152.

Bartholomew, H., Osborne, J. \& Ratcliffe, M. (2004). Teaching students 'ideas-about-science': Five dimensions of effective practice. Science Education, 88(5), 655-682.

Bravo, L. A., Merce, I., \& Anna, E. (2001, April). A characterisation of practical proposals to teach the philosophy of science to prospective science teachers. Paper presented at the IOSTE Symposium, Paralimni, Cyprus. 
Can, B., \& Pekmez, E. Ş. (2010). Bilimin doğası etkinliklerinin ilköğretim yedinci sınıf öğrencilerinin bilimsel süreç becerilerinin geliştirilmesindeki etkisi. Pamukkale Üniversitesi Ĕ̆itim Fakültesi Dergisi, (27), 113-123.

Canbazoğlu, S. (2008). Fen bilgisi ögretmen adaylarının maddenin tanecikli yapısı ünitesine ilişkin pedagojik alan bilgilerinin değerlendirilmesi. (Yayımlanmamış Yüksek Lisans Tezi). Gazi Üniversitesi Eğitim Bilimleri Enstitüsü, Ankara.

Carey, S. \& Evans, R. (1989). An experiment is when you try it and see if it works: A study of grade 7 students' understanding of the construction of scientific knowledge. International Journal of Science Education, 11(5), 514-529.

Chen, S. (2001). Prospective teachers' views on the nature of science and science teaching. (Unpublished Doctoral Dissertation) Indiana University, Indiana, USA.

Çakıcı, Y. (2009). Fen Eğitiminde Bir Önkoşul: İlimin doğasını anlama. M.Ü. Atatürk Eğitim Fakültesi Eğitim Bilimleri Dergisi, (29), 57-74

Çetin, P. S. (2009). Effect of conceptual change oriented instruction on understanding of gases concepts. (Unpublished Doctoral Thesis). Middle East Technical University, Ankara 2009.

Çınar, M. \& Köksal, N. (2013). Sosyal bilgiler öğretmen adaylarının bilime ve bilimin doğasına yönelik görüşleri. Mersin Üniversitesi Ĕ̈itim Fakültesi Dergisi, 9(2), 43-57.

Deniz, H. \& Adibelli, E. (2015). Exploring how second grade elementary teachers translate their nature of science views into classroom practice after a graduate a level nature of science course. Research in Science Education, 45(6), 867-888.

DiGiuseppe, M. (2013). Representing nature of science in a science textbook: Exploring author-editorpublisher interactions. International Journal of Science Education, 36(7), 1061-1082

Doğan, N., Çakıroğlu J., Çavuş, S., Bilican, K. \& Arslan, O. (2011). Öğretmenlerin bilimin doğası hakkındaki görüşlerinin geliştirilmesi: hizmetiçi eğitim programının etkisi. Hacettepe Üniversitesi Eğitim Fakültesi Dergisi, 40(2011) 127-139.

Doğan, B. N. (2005). Türkiye genelinde ortaöğretim fen branşı öğretmen ve öğrencilerinin bilimin doğası üzerine görüşlerinin araştırılması, (Yayınlanmamış Doktora Tezi). Gazi Üniversitesi, Ankara, .

Doğan-Bora, N., Arslan, O. \& Çakıroğlu, J. (2006). Lise öğrencilerinin bilim ve bilim insanı hakkındaki görüşleri. Hacettepe Üniversitesi Ĕ̈itim Fakültesi Dergisi, 31(31), 32-44.

Erdoğan, R. (2004). Investigation of the preservice science teachers' views on nature of science. (Yayınlanmamış Yüksek Lisans Tezi). Orta Doğu Teknik Üniversitesi, Ankara. 
Yllmaz, Çimen, \& Karakaya

Gess-Newsome J. (2002). The use and impact of explicit instruction about the nature of science and science inquiry in an elementary science methods course. Science \& Education, 11(1), 55-67.

Hanuscin, D., Lee, M. H. \& Akerson, V. L. (2011). Elementary teachers' pedagogical content knowledge for teaching the nature of science. Science Education, 95(1), 145-167. DOI: 10.1002/sce.20404.

Kang, S., Scharmann, L. C., \& Noh, T. (2005). Examining students' views on the nature of science: Results from Korean 6th, 8th, and 10th graders. Science Education, 89(2), 314-334.

Khishfe R. \& Abd-El-Khalick F. (2002). Influence of explicit and reflective versus implicit inquiryoriented instruction on sixth graders' views of nature of science. Journal of Research in Science Teaching, 39(7), 551-578.

Khishfe, R. (2008). The development of seventh graders' views of nature of science. Journal of Research in Science Teaching, 45(4), 470-496.

Köseoğlu, F., Tümay, H., \& Üstün, U. (2010). Bilimin Doğası Öğretimi Mesleki Gelişim Paketinin Geliştirilmesi ve Öğretmen Adaylarına Uygulanması İle İlgili Tartışmalar. Journal of Kirsehir Education Faculty, 11(4), 129162.

Leden, L., Hansson, L., Redfors, A. \& Ideland, M. (2015). Context-rich vs. context-stripped approach to NOS teaching: teachers' reflections. In The 11th Conference of the European Science Education Research Association (ESERA), Helsinki, August 31-September 4, 2015.

Lederman, N. (1999). Teachers' understanding of the nature of science and classroom practice: Factors that facilitate or impede the relationship. Journal of Researching Science Teaching, 36(8), 916- 929.

Lederman, N. G. (1992). Students' and teachers' conceptions of the nature of science: A review of the research. Journal of Research in Science Teaching, 29(4), 331-359.

Lederman, N. G. \& Lederman, J. S. (2004). Project ICON: A professional development project to promote teachers' and students' knowledge of nature of science and scientific inquiry. In Buffler, A. \& Laugksch, R. (Eds.) Proceedings of the 12th annual conference of the Southern African Association for research in Mathematics, Science and technology education. Durban: SAARMSTE.

Matthews, M. (2000). Time for science education: How teaching the history and philosophy of pendulum motion can contribute to science literacy. NY: Plenum Publishers.

McComas, W. F., \& Olson, J. K. (1998). International science education standards documents (41-52). In McComas (Ed.) The Nature of Science in Science Education: Rationales and Strategies. The Netherlands: Kluwer Academic Publishers.

MEB. (2005). İlköğretim Fen ve Teknoloji Dersi (6, 7 ve 8. Sinıflar) Öğretim Programı. Ankara: MEB Yayınevi. 
MEB. (2013). İlköğretim Kurumları (Illkokullar ve Ortaokullar) Fen Bilimleri Dersi (3, 4, 5, 6, 7 ve 8. Sinıflar) Ögretim Programı, Ankara: MEB Yayınevi.

MEB. (2017). Ortaöğretim Kurumları Biyoloji Dersi Öğretim Programı (9,10,11 ve 12. Sinıflar), Ankara: MEB Yayınevi.

Mıhladız G. (2010). Fen bilgisi öğretmen adaylarının bilimin doğası konusundaki pedagojik alan bilgilerinin araştırılması. (Yayımlanmamış Doktora Tezi). Gazi Üniversitesi, Ankara.

Mıhladız, G., \& Doğan, A. (2012). Fen ve teknoloji öğretmenleri ve öğretmen adaylarının bilimin doğası konusundaki alan bilgilerinin karş1laştırılması. E-International Journal of Educational Research, 3(1), 78-96.

Murcia, K. \& Schibeci, R. (1999). Primary student teachers' conceptions of the nature of science. International Journal of Science Education, 21(11), 1123-1140.

National Research Council (1996). National Science Education Standards. Washington, DC: National Academy Press.

Posnanski, T. J. (2010). Developing understanding of the nature of science within a professional development program for inservice elementary teachers: project nature of elementary science teaching. Journal of Science Teacher Education, 21(5), 589-621.

Ratcliffe, M. (2008, June). Pedagogical content knowledge for teaching concepts of the Nature of Science. Paper presented at the Nordic Symposium on Science Education, University of Iceland, Reykjavik, Iceland. Retrieved September 8, 2008, from http:// symposium9.khi.is/synopsis/nfsun9_submission_5.doc

Rivas, M.G.(2003). The nature of science and preservice elementary teacher: change in understanding and practice, (Yayımlanmamıs Doktora Tezi) University of California.

Roberts, D. A. (2007). Scientific Literacy/Science Literacy. In S. A. Abell \& N. G. Lederman (Eds.), Handbook of research on science education (pp.729-780). Mahwah, NJ: Lawrance Erlbaum Associates, Publishers.

Roberts, R. (2001).Procedural understanding in biology: The thinking behind the doing. The Journal of Biological Education, 35(3),113-117.

Solomon, J., Scott L. \& Duveen J. (1996). Large-Scale exploration of pupils' understanding of the nature of science. Science Education, 80(5),493-508.

Taber, K. S. (2008). Towards a curricular model of the nature of science. Science \& Education,17(2-3), 179-218.

Tairab, H. H. (2001). How do pre-service and in-service science teachers view the nature of science and technology. Research in Science and Technological Education, 19(2), 235-250. 
Yllmaz, Çimen, \& Karakaya

Taşar, M. F. (2003). Teaching history and the nature of science in science teacher education programs. Pamukkale Üniversitesi Eğitim Fakültesi Dergisi, 7(1), 30-42.

Timur, S., Karatay, R., \& Timur, B. (2013). 2005 ve 2013 yılı fen dersi öğretim programlarının karşılaştırılması. Adıyaman Üniversitesi Sosyal Bilimler Enstitüsü Dergisi, 6(15), 233-264.

Tsai, C. (2002). Nested epistemologies: science teachers' beliefs of teaching, learning and science. International Journal of Science Education, 24(8),771-783.

Vesterinen, V. M., Akesla, M., \& Lavonen, J. (2013). Quantitative analysis of representations of nature of science in Nordic upper secondary school textbooks using framework of analysis based on philosophy of chemistry. Science \& Education, 22(7), 1839-1855.

Water-Adams S. (2006). "The relationship between understanding of the nature of science and practice: The influence of teachers beliefs about education”. International Journal of Science Education 28(8), 919-944.

Yakmac1, B. (1998). Science (biology, chemistry and physics) teachers' views on the nature of science as a dimension of scientific literacy. (Yayınlanmamış Master Tezi). Boğaziçi Üniversitesi, İstanbul, Türkiye.

Zeidler, D. L., Walker, K. A., Ackett, W. A \& Simmons, M. L. (2002). Tangled up in views: Beliefs in the nature of science and responses to socioscientific dilemmas. Science Education, 86(3), 343-367.

Zorlu, Y. \& Baykara O. (2015). Teknoloji bilimin uygulaması mıdır? Fen ve teknoloji öğretmen adaylarının görüşleri. Atatürk Üniversitesi Kazım Karabekir Eğitim Fakültesi Dergisi, (29), 123-144. 